\section{PERCEIVED VISUAL CGI FAMILIARITY TOWARDS UNCANNY VALLEY THEORY IN FILM}

\author{
Ahmad Azaini Manaf \\ Faculty of Applied and Creative Arts, \\ Universiti Malaysia Sarawak.

\section{Siti Nor Fatihah Ismail} \\ Faculty of Applied and Creative Arts, \\ Universiti Malaysia Sarawak.

\section{Mohd Rosli Arshad} \\ Animation Department, \\ Universiti Kuala Lumpur, Malaysia.
}

Corresponding Author

amaazaini@unimas.my
In the enhancement of the advanced technology, the uncanny valley is becoming a high-stakes concern of the entertainment industry to produce good films and animations (Chaminade et al., 2007). Therefore, this study aims to analyse participants' familiarity towards the usage of digital characters as actors. Then, this article is to convey on how the uncanny valley factors affect audience's attention in watching films with computer graphic imagery (CGI) elements in films. The researcher has selected visual stimuli that are divided into (4 $\times 4$ factorial design) with 2 subjects of realistic and accurate human characters, meanwhile the second stimuli, researcher selected 2 subjects with minimum characteristic of human likeness. The surveys conducted are self-administered manner with combination of videos and images, distributed online via email and social network. This research concludes, the more familiarity and expectations of the audiences, the higher discomfort feeling when looking to a CGI made character. This illustrates that the longer a duration of $C G$ actors in action, the higher significant weaknesses and substantial of superficial visuals. Therefore, this research is beneficial to assists artists and digital creative directors in digital actor's creation, and guidance for developing more realistic actors in future projects.

Keywords: animation, humanoid reality, uncanny valley, virtual reality, visual analysis. 


\section{INTRODUCTION}

\section{What is uncanny valley?}

The uncanny valley theory was proposed by Masahiro Mori in 1970 regarding the psychological effects of lifelike robotics (Mori, MacDorman, \& Kageki, 2012). The uncanny valley is a phenomenon that occurs in robotics and depicted in animation, wherein things that look extremely like the human face but differ slightly from its natural appearance or from its natural movements and expressions, are perceived to be disturbing, uncanny, and revolting. Also, according to (Seyama \& Nagayama, (2007), the hypothesis of the uncanny valley is not limited to robots, but also applicable to any type of human-like object, such as dolls, masks, facial caricatures, avatars in virtual reality, and CG actors in movies. The uncanny valley also refers to a sense of unease and discomfort when people look at very realistic virtual humans. (Brenton, Gillies, Ballin, \& Chatting, 2005).

On the other hand, the name uncanny valley refers to a point on a graph that plots the human likeness of a robot or virtual character in relation to its perceived familiarity, as can be seen in Figure 1. In the initial stages, perception of familiarity increases as human likeness increases, but at a certain point, when the likeness is perceived as extremely similar and yet not similar enough, the graph decreases drastically to negative values of familiarity. This is called the uncanny valley. The situation, however, does not last long. As the robot's human likeness continues to grow, negative perceptions fade, and once again the robot is perceived as more familiar (Mori, 1970).

Mori's graph has been criticized on the grounds that familiarity is difficult to define and that it is difficult to determine which emotion accurately represents the opposite of familiarity, and that the word "familiarity" itself may not actually be an accurate description of a positive human response to human-like entities (Ho, Macdorman, \& Pramono, 2008).

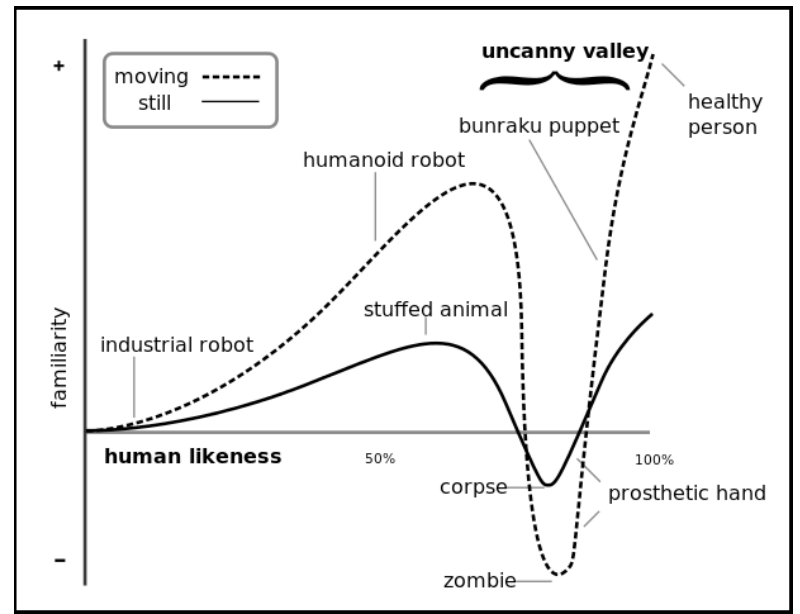

Figure 1: Uncanny Valley Graph (Mori, 1970)

The study is an evaluation on how specific audience perceived value of $3 \mathrm{D}$ characters that are presented in movies and films. Among the preliminary questions in this research are: Does the uncanny valley exists in $3 \mathrm{D}$ actors? Does Uncanny valley theory important? and it is affecting the film itself? If it so, what is the relationship between uncanny valley with film? 


\section{METHOD}

The research was constructed with two components. The first component, the selected visual stimuli are divided into 2 subjects of realistic and accurate human characters. In second component, the researcher selected 2 subjects with less characteristics of human likeness. The subjects; the digital actors and character, was presented with still photos, accompanied with a video sequence of the actors and characters. In summary, a two-stages of questionnaire distribution were conducted which has two components based $4 \times 4$ factorial subjects (actors and characters) in video sequence and images.

The sampling method were selected from undergraduate animation students in Kuching,Sarawak and Peninsular Malaysia, and the responses were $n=123$. The third component was to execute self-administered surveys with videos and images, where the survey was distributed online via email and social network. Participants are required to rate all video and images embedded on the questionnaires. All of the visuals (CG actors) represents well-known characters from the most recent films. The justification function was to evaluate the participants ability to identify the chosen characters.

\subsection{Measurements}

The set of questions has been developed in Table 1. In this test, mean Definition 1 and Levene $F$-test were executed to obtain the certain discrepancies between variables. Mean is the most commonly used measure of central tendency hence is a good representative of the data. Then, the Levene's test (ANOVA) in Definition 2 was executed to obtain F-test results of the variance across groups.

$$
\mu=\sum x p(x)
$$

\section{Definition 1 Mean expected value}

Where,

$\mu:$ mean

$x$ : An outcome

$\mathrm{p}(\boldsymbol{x})$ : probability if that outcome

$$
W=\frac{(N-k)}{(k-1)} \cdot \frac{\sum_{i=1}^{k} N_{i}\left(Z_{i .}-Z_{. .}\right)^{2}}{\sum_{i=1}^{k} \sum_{j=1}^{N_{i}}\left(Z_{i j}-Z_{i .}\right)^{2}}
$$

Definition 2 Levene's Test

\footnotetext{
Where,

$\boldsymbol{k}$ is the number of different groups to which the sampled cases belong

$\boldsymbol{N}_{\boldsymbol{i}}$ is the number of cases in the $i^{\text {th }}$ group

$\boldsymbol{N}$ is the total number of cases in all group

$Z_{i j}=\left|Y_{i j}-\bar{Y}_{i}\right|, \bar{Y}_{i,}$ is the mean of the $i^{\text {th }}$ group

$\left|Y_{i j}, \tilde{Y}_{i}.\right|, \tilde{Y}_{i}$ is the median of the $i^{\text {th }}$ group

$Y_{i j}$ is the value of the measured variable for the $i^{t \text { th }}$ case from the $i^{\text {th }}$ group.

$Z_{i}=\frac{1}{N} \sum_{j=1}^{N_{i}} Z_{i j}$ is the mean of the $Z_{i j}$ for group $i$

$Z_{. .}=\frac{1}{N} \sum_{i=1}^{k} \sum_{j=1}^{N_{i}} Z_{i j}$ is the mean of all $Z_{i j}$
} 
The output of Levene's test were executed using SPSS, with the rule of thumb in Levene's output required significant value of $<0.05$. This however requires sequential procedure as similar to Homogeneity of Variances. This holds the results of the main outcome of this research with Levene's output as below:

Levene's $F$ test in the assumption of homogeneity of variances was tested and shows moderate results in Princess Leia (Carrie Fisher) in still image, $F(3,119)=1.05 p=.374$ and $F(3,119)=2.27 p=.084$ for video sequence.

\subsection{The Characters}

The variables on the characters were justified based of the film success, and the characters or actors required familiarity factors among the audiences. Thus, the questions were prepared according to the measurement for the test. The first set for the criteria were the human likeness and realistically required in each character. This feature is necessary, and it is a requirement to process results to uncanny valley graph (the horizontal axis), as in Figure 1. The second criteria was created if the character were unfamiliar to the respondent. It is important to note; the goal was to cover the widest range of features in uncanny valley properties as possible.

In realistic variables, the test evaluates the human likeness feature, the assessment recommended characters that represent accurate human as possible "Dr. Strange" (S2 in Table 1). Cartoon characters were selected to represent the least human likeness such as, character of Miguel (S4) from "COCO" movie. To cover many intermediate possibilities in this range, least human likeness character, moustache Dad-Tim Lockwood from the movie "Cloudy with a Chance of Meatball 2" (S3) is recommanded.

In looking into the familiarity of characters, the assessment on originality of the main characters of the film is studied. Therefore, the test recommended Princess Lea from the "Rogue One: A Star Wars Story" movie (St1), like S2 from "Dr. Strange" film, the character of Tim Lockwood from the film "Cloudy with a Chance of Meatball 2" S3, and other S4 from movie "Coco". The familiarity factors are required in the test, as all the characters selected were from the recently released films worldwide.

There are certain considerations and expected limitations in choosing the right characters. The expression in the video needed to be neutral, accurate and humanly possible. The sequential assessment was to observe actual human versus CGI version. The selected human being character required to be embedded in a natural environment, in other words, "natural". Table 1 shows the complete lists of characters mentioned in the survey with detailed description of name, title of film, and name of digital actors. 
Table 1: The Actors/Characters presented in the survey and the origin of them.

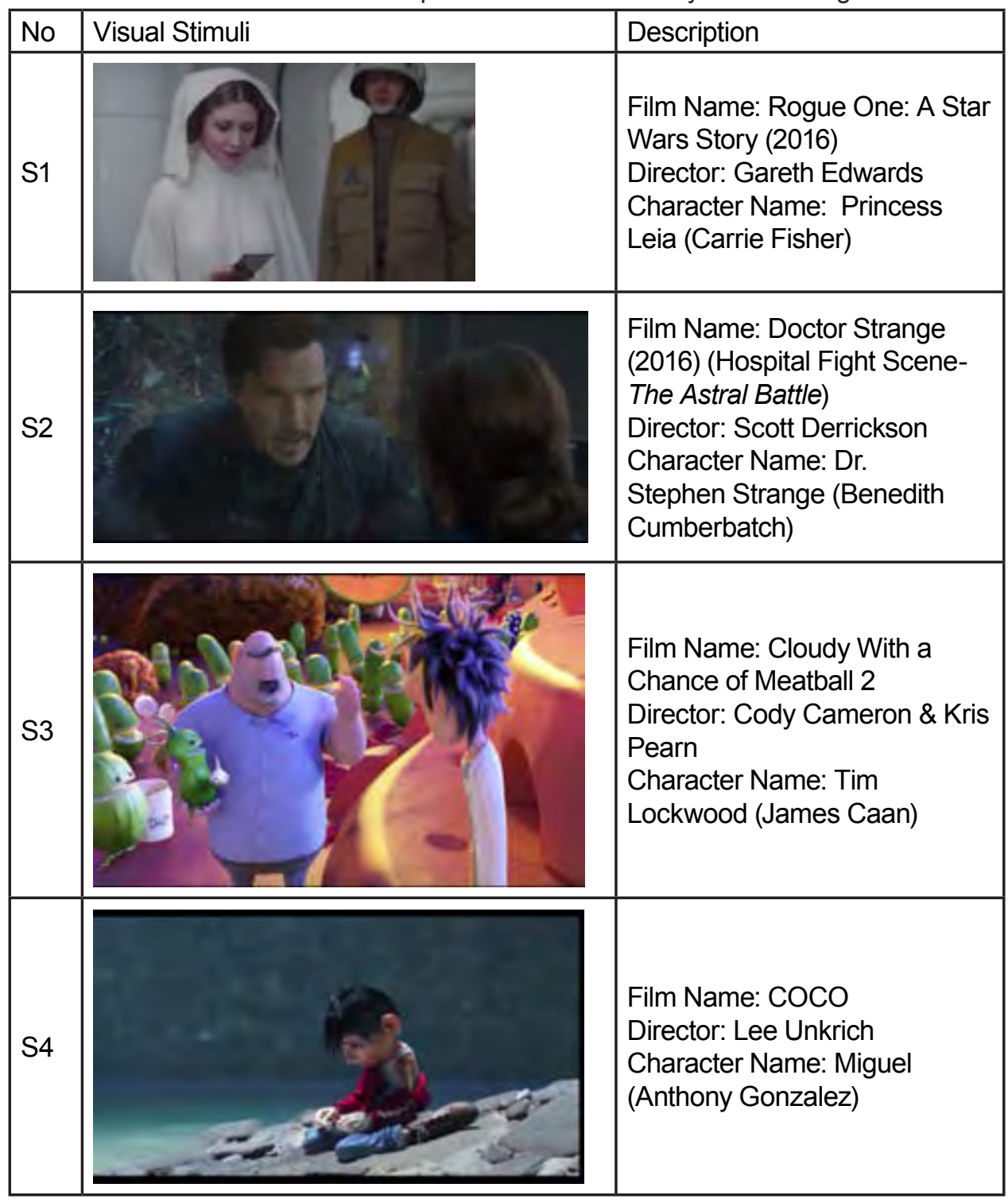

\subsection{The Questionnaire}

The questionnaire constructed in the test covers the questions listed in Table 2 respectively. The participants are required to indicate their feeling about the character in a subjective manner. The construction of the questions were in specific manner and economical as possible, due to the level of demographics of the participants, to avoid misinterpretation.

Based on the main research goals in finding Uncanny Valley, each participant is required to identify strangeness or discomfort feeling while watching the digital actors. The reason was to fit the concept of uncanny valley. There are also additional questions required on their response to the realistic level of human likeness, based on their observation. 
Table 2: The questions of the survey's form

\begin{tabular}{|c|c|c|}
\hline Question & Alternative & Type of Question \\
\hline $\begin{array}{l}\text { Are you familiar } \\
\text { with the character } \\
\text { above? }\end{array}$ & $\begin{array}{l}\text { a. Yes } \\
\text { b. No } \\
\text { c. Don't Know }\end{array}$ & Single Choice \\
\hline $\begin{array}{l}\text { Do you think the } \\
\text { characters in the } \\
\text { picture above } \\
\text { indicates realistic } \\
\text { character? }\end{array}$ & $\begin{array}{l}\text { a. Yes } \\
\text { b. No } \\
\text { c. Don't Know }\end{array}$ & Single Choice \\
\hline $\begin{array}{l}\text { If YES, how } \\
\text { realistic does it } \\
\text { seem? }\end{array}$ & $\begin{array}{l}\text { a. Very Realistic } \\
\text { b. Moderately Realistic } \\
\text { c. Unrealistic } \\
\text { d. Don't Know }\end{array}$ & Single Choice \\
\hline $\begin{array}{l}\text { 4. Do you feel } \\
\text { discomfort } \\
\text { (strangeness) } \\
\text { when looking to } \\
\text { the character? }\end{array}$ & $\begin{array}{l}\text { a. Yes } \\
\text { b. No } \\
\text { c. Don't Know }\end{array}$ & Single Choice \\
\hline $\begin{array}{l}\text { Does the } \\
\text { character above makes } \\
\text { you feel } \\
\text { eerie (frighten) }\end{array}$ & $\begin{array}{l}\text { a. Yes } \\
\text { b. No } \\
\text { c. Don't Know }\end{array}$ & Single Choice \\
\hline $\begin{array}{l}\text { Which part most } \\
\text { influenced in the } \\
\text { discomfort when looking } \\
\text { to the character? }\end{array}$ & $\begin{array}{l}\text { a. Face } \\
\text { b. Upper Body } \\
\text { c. Lower Body } \\
\text { d. Character Movement }\end{array}$ & Single Choice \\
\hline
\end{tabular}

\section{RESULT}

The results of responses were $\mathrm{N}=123$ within two weeks distributions of questionnaires. The analysis was then processed using IBM SPSS version 23. In the early stage, a Cronbach's Alpha test is used to ensure that all of the variables are reliable and relevant. All 48 items of alpha coefficient showing good internal consistency of .806 as results as shown in Table 3 .

Table 3: The Reliability Statistics

\begin{tabular}{|c|l|c|}
\hline $\begin{array}{l}\text { Cronbach's } \\
\text { Alpha }\end{array}$ & $\begin{array}{l}\text { Cronbach's } \\
\text { Alpha Based on } \\
\text { Standardized } \\
\text { Items }\end{array}$ & N of Items \\
\hline .806 & \multicolumn{1}{|c|}{.842} & 48 \\
\hline
\end{tabular}

The results in Table 4 shows moderate realistic level of the character for the both S1 (still images) and V1 (video) user's familiarity were not significant with $(M=1.28,1.19)$ and the unrealistic level of the character with significantly higher for the S1 (still images) and V1 (video) user's familiarity with $(M=1.50,1.56)$. Also, the assumption of normality was evaluated and determined to be moderate as the three groups' distribution with Skew and Kurtosis were less than |2.0|and |9.0|, respectively (Schmider, Ziegler, Danay, Beyer, \& Bühner, 2010). 
In the sequence of test, the assumption of homogeneity of variances was tested and shows moderate results based on Levene's $F$ test in Table 5 for S1 (still image), $F(3,119)=1.05 p$ $=.374$ and $F(3,119)=2.27 p=.084$ for $\mathrm{V} 1$ (video).

Table 4: Descriptive statistic for the users' familiarity across the character realistic level for stimuli 1 .

\begin{tabular}{|l|l|l|l|l|l|}
\hline S1 & Mean & $\mathrm{N}$ & $\begin{array}{l}\text { Std. } \\
\text { Deviation }\end{array}$ & Kurtosis & Skewness \\
\hline Very Realistic & 1.2881 & 59 & .52689 & 2.003 & 1.668 \\
\hline $\begin{array}{l}\text { Moderately } \\
\text { Realistic }\end{array}$ & 1.2800 & 50 & .60744 & 3.054 & 2.060 \\
\hline Unrealistic & 1.5000 & 4 & .57735 & -6.000 & .000 \\
\hline V1 & Mean & $\mathrm{N}$ & $\begin{array}{l}\text { Std. } \\
\text { Deviation }\end{array}$ & Kurtosis & Skewness \\
\hline Very Realistic & 1.3134 & 67 & .52826 & 1.210 & 1.443 \\
\hline $\begin{array}{l}\text { Moderately } \\
\text { Realistic }\end{array}$ & 1.1951 & 41 & .45932 & 5.362 & 2.375 \\
\hline Unrealistic & 1.5556 & 9 & .52705 & -2.571 & -.271 \\
\hline & & & & & \\
\hline
\end{tabular}

Table 5: Test of Homogeneity Variance for stimuli 1

\begin{tabular}{|l|l|l|l|l|}
\hline Stimuli & $\begin{array}{l}\text { Levene } \\
\text { Statistic }\end{array}$ & df1 & df2 & Sig. \\
\hline S1 & 1.049 & 3 & 119 & .374 \\
\hline V1 & 2.268 & 3 & 119 & .084 \\
\hline
\end{tabular}

In addition, Table 6 shows the realistic level of the character was significantly lower for the S2 (still images) and V2 (video) user's familiarity with $(M=1.00,1.02)$ in comparison to the realistic level of the character with highly significant for the S2 (still images) and V2 (video) with $(M=1.13,1.15)$. Then, assumption of homogeneity of variances shown in Table 7 was tested and shows sufficient level in Levene's $F$ test for S2 (still image), $F(3,119)=4.90 p=$ .003 and for the V2 (video), $F(3,119)=12.11 p=.000$.

Table 6: Descriptive statistic for the users' familiarity across the character realistic level for stimuli 2 .

\begin{tabular}{|l|l|l|l|l|l|}
\hline S2 & Mean & $\mathrm{N}$ & Std. Deviation & Kurtosis & Skewness \\
\hline Very Realistic & 1.0909 & 77 & .40334 & 18.689 & 4.441 \\
\hline Moderately Realistic & 1.1351 & 37 & .34658 & 3.120 & 2.226 \\
\hline Unrealistic & 1.0000 & 4 & .00000 &. &. \\
\hline V2 & Mean & $\mathrm{N}$ & Std. Deviation & Kurtosis & Skewness \\
\hline Very Realistic & 1.0263 & 76 & .16114 & 35.391 & 6.038 \\
\hline Moderately Realistic & 1.1111 & 27 & .32026 & 5.265 & 2.623 \\
\hline Unrealistic & 1.1538 & 13 & .37553 & 3.223 & 2.179 \\
\hline
\end{tabular}


Table 7: Test of Homogeneity Variance for stimuli 2

\begin{tabular}{|l|l|l|l|l|}
\hline Stimuli & $\begin{array}{l}\text { Levene Sta- } \\
\text { tistic }\end{array}$ & df1 & df2 & Sig. \\
\hline S2 & 4.905 & 3 & 119 & .003 \\
\hline V2 & 12.119 & 3 & 119 & .000 \\
\hline
\end{tabular}

In Table 8, the very realistic level of the character was non-significant for the both S3 (still images) and V3 (video) user's familiarity with $(M=1.11,1.00)$ and the unrealistic level of the character shows significant for both still images and video, with user's familiarity with $(M=1.30,1.29)$. Then, the assumption of homogeneity of variances was tested and shows acceptable results in Levene's $F$ test for S3 (still image), $F(3,119)=8.18 p=.000$ and for the V3 $($ video $) F(3,119)=16.97 p=.000$ is shown in Table 9.

Table 8: Descriptive statistic for the users' familiarity across the character realistic level for stimuli 3.

\begin{tabular}{|l|l|l|l|l|l|}
\hline S3 & Mean & $\mathrm{N}$ & Std. Deviation & Kurtosis & Skewness \\
\hline Very Realistic & 1.1111 & 9 & .33333 & 9.000 & 3.000 \\
\hline Moderately Realistic & 1.1429 & 35 & .35504 & 2.705 & 2.134 \\
\hline Unrealistic & 1.3065 & 62 & .49881 & .513 & 1.264 \\
\hline V3 & Mean & $\mathrm{N}$ & Std. Deviation & Kurtosis & Skewness \\
\hline Very Realistic & 1.0000 & 18 & .00000 &. &. \\
\hline Moderately Realistic & 1.1429 & 35 & .35504 & 2.705 & 2.134 \\
\hline Unrealistic & 1.2909 & 55 & .53308 & 2.052 & 1.681 \\
\hline
\end{tabular}

Table 9: Test of Homogeneity Variance for stimuli 3

\begin{tabular}{|l|l|l|l|l|}
\hline Stimuli & $\begin{array}{l}\text { Levene Sta- } \\
\text { tistic }\end{array}$ & df1 & df2 & Sig. \\
\hline S3 & 8.183 & 3 & 119 & .000 \\
\hline V3 & 16.967 & 3 & 119 & .000 \\
\hline
\end{tabular}

Table 10 shows the realistic level of the character. The result shows less significant for both S4 (still images) and V4 (video) $(M=1.26,1.12)$ and the unrealistic level of the character with significantly high for $\mathrm{S} 4$ (still images) user's familiarity with $(M=1.34)$ and for the $\mathrm{V} 4$ (video), the moderately realistic level was significantly high with $(M=1.29)$. The Levene's $F$ test for S4 (still image) showed, $F(3,119)=3.01 p=.033$ and $F(3,119)=8.56 p=.000$ for the V4 (video) was tested and with acceptable results shown in Table 11. 
Table 10: Descriptive statistic for the users' familiarity across the character realistic level for stimuli 4 .

\begin{tabular}{|l|l|l|l|l|l|}
\hline S4 & Mean & $\mathrm{N}$ & Std. Deviation & Kurtosis & Skewness \\
\hline Very Realistic & 1.2609 & 23 & .44898 & -.709 & 1.167 \\
\hline Moderately Realistic & 1.2708 & 48 & .49420 & 1.760 & 1.604 \\
\hline Unrealistic & 1.3429 & 35 & .53922 & .758 & 1.278 \\
\hline V4 & Mean & $\mathrm{N}$ & Std. Deviation & Kurtosis & Skewness \\
\hline Very Realistic & 1.1250 & 24 & .33783 & 4.210 & 2.422 \\
\hline Moderately Realistic & 1.2963 & 54 & .46091 & -1.203 & .918 \\
\hline Unrealistic & 1.2727 & 33 & .45227 & -.915 & 1.070 \\
\hline
\end{tabular}

Table 11: Test of Homogeneity Variance for stimuli 4

\begin{tabular}{|l|l|l|l|l|}
\hline Stimuli & $\begin{array}{l}\text { Levene } \\
\text { Statistic }\end{array}$ & df1 & df2 & Sig. \\
\hline S4 & 3.017 & 3 & 119 & 0.33 \\
\hline V4 & 8.557 & 3 & 119 & .000 \\
\hline
\end{tabular}

\section{CONCLUSION AND DISCUSSION}

The results obtained show discrepancy between the effects of the uncanny valley and the familiarity of the characters to the audience. Interestingly, based on the results, human likeness were significantly high; mean $=1.2881, \mathrm{SD}=.52689$ for Princess Lea in Rogue One: A Star Wars Story (2016) compared to stimuli 2 Dr. Strange (2016) which shows weak visuals of Dr. Strange footage (Hospital Fight Scene- The Astral Battle). In Figure 2 below, frame 8 depicted in cartoonic effect as a result from the captured footage. This is to conclude that the longer a duration of CG actors in action, the further significant weaknesses and substantial of superficial visuals. There is also another research which supports the theory conducted by Uggah \& Manaf (2015) who suggested that animation styles and techniques should not only focus on avoiding realistic animation but instead on other factors such as target audiences and the animation's genre. As a result, the visuals will create unpleasant impression, which strengthen the theory of uncanny valley.
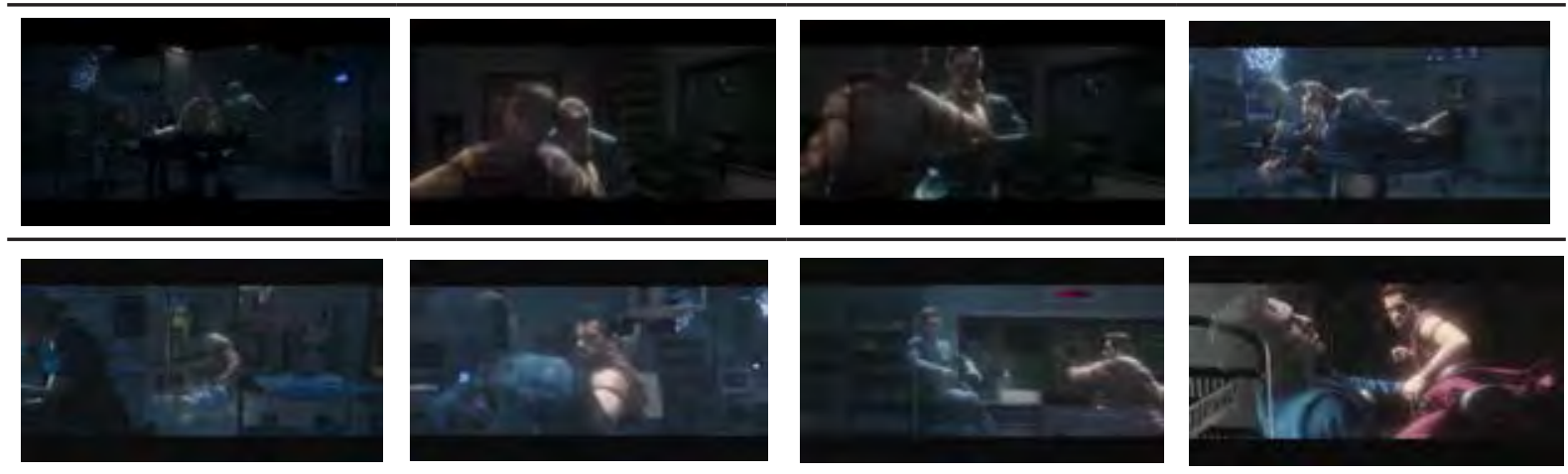

Figure 2: Dr. Strange (2016) (Hospital Fight Scene- Astral Battle) retrieved from https://www.youtube. com/watch?v=oh0f7LWcF-o (Superheroes, 2018) 
Future work may be able to revisit the uncanny valley subject under a similar approach in order to differentiate the effects and duration of the main role in CG application in movies and films. For future digital artists, this research might in fact used as guidance for developing more realistic actors in future projects.

\section{ACKNOWLEDGEMENT}

This research article was supported by UNIMAS Special Grant Scheme F03/SpGS/1545/2017.

\section{REFERENCES}

Brenton, H., Gillies, M., Ballin, D., \& Chatting, D. (2005). The uncanny valley: Does it exist and is it related to presence. Proc. of British $\mathrm{HCl}$ Group Annual Conference: HumanAnimated Characters Interaction Workshop, (2004), 1-8.

Chaminade, T., Hodgins, J. K., Letteri, J., \& MacDorman, K. F. (2007). The uncanny valley of eeriness. SIGGRAPH '07: ACM SIGGRAPH 2007 Panels, 1. https://doi.org/http://doi. acm.org/10.1145/1278400.1278402

Ho, C.C, Macdorman, K.F, \& Pramono, Z. (2008). Human emotion and the uncanny valley: A GLM, MDS, and ISOMAP analysis of robot video ratings, (January), 169-176. https://doi. org/10.1145/1349822.1349845

Mori, M., MacDorman, K. F., \& Kageki, N. (2012). The uncanny valley. IEEE Robotics and Automation Magazine, 19(2), 98-100. https://doi.org/10.1109/MRA.2012.2192811

Schmider, E., Ziegler, M., Danay, E., Beyer, L., \& Bühner, M. (2010). Is It Really Robust? Methodology, 6(4), 147-151. https://doi.org/10.1027/1614-2241/a000016

Seyama, J., \& Nagayama, R. S. (2007). The uncanny valley: Effect of realism on the impression of artificial human faces. Presence: Teleoperators and Virtual Environments, 16(4), 337-351. https://doi.org/10.1162/pres.16.4.337

Superheroes, J. (2018). DOCTOR STRANGE (2016) Movie Clip - Battle in the Astral Plane HD. JoBlo Superheroes. Retrieved from https://www.youtube.com/channel/ UCkRBmTHNrKc6CF6scF_y5kw

Uggah, L. L., \& Manaf, A. (2015). Evaluating the Uncanny Valley Theory Based on Human Attitudes. Archives of Design Research, 28(2), 27. https://doi.org/10.15187/ adr.2015.05.28.2.27 